Bulletin, 1993, 17, 774) 'Personality disorder a declining diagnosis'. In the present 'politically correct' climate the diagnosis of personality disorder seems very 'non-PC'.

Its use as a means of labelling an annoying patient is indefensible - but properly used it can give much information about past, present and future behaviour. Just as all diagnoses are 'labels' they give more information, not less, enabling one to make informed management decisions, taking advantage of previous assessments and experience.

Perhaps the answer, as with many non-PC terms, is to change the name. Personality Challenged or Otherwise Personality Gifted, are two possibilities although I would be pleased to hear other suggestions.

Caroline Mulligan, Windsor Day Hospital, Llverpool

\section{The value of child and adolescent psychiatry}

Sir: Dr Hermson (Psychiatric Bulletin, 1993, 17. 628) and Dr Kirby (Psychiatric Bulletin April $1994,18,246$ ) both emphasise the value of early experience in child and family psychiatry as part of the training for all psychiatrists.

Some years ago Peter Hill and I published an article making similar arguments (Bulletin of the Royal College of Psychiatrists, 1987, 11, 19-21).
We pointed out that approximately one quarter of the population is under the age of 18 and that this group has an appreciable psychiatric morbidity. All psychiatrists should known about this and about the services available for children and families. We suggested that all psychiatrists in training would benefit from a child psychiatry placement, as senior house officer or registrar. Useful training experiences would include practice at taking a developmental perspective in formulating problems, opportunities to interview the developmentally young and take part in conjoint family interviews, working within a service which emphasises the wider family and social context of patients, observing and taking part in a wide range of psychological treatment methods, and participating in a multidisciplinary team. We suggested that child psychiatrists should structure training differently for trainees who do not intend to pursue a career in child and adolescent psychiatry and provided a checklist of training opportunities.

Experience in child and adolescent psychiatry is just as relevant today for future adult psychiatrists as it was when we wrote the article. It is of interest that trainees too support the value of child and adolescent psychiatry irrespective of future psychiatric career. Clinical tutors and the central approval panel should take note.

DAVID COTTRELl, Untuersity of Leeds, $12 a$ Clarendon Road, Leeds LS2 9NN

\title{
Corrigendum
}

The names of the authors of the letter 'Age and sex differences in general practice benzodiazepine prescription in United Kingdom'
(Psychiatric Bulletin, 18, 376-377) should read: V. Eapen. N. Savla and A. Khan. 